\title{
Thermal behaviour of metal soaps from biodegradable rubber seed oil
}

\author{
D. Balköse · T. O. Egbuchunam • F. E. Okieimen
}

IVMTT2009 Special Chapter

(C) Akadémiai Kiadó, Budapest, Hungary 2010

\begin{abstract}
Soaps are a class of surface active compounds derived from natural oils and fats. Double decomposition reactions permit the synthesis of metallic soaps, which are long-chain carboxylates of metal ions, from alkaline ones such as sodium, potassium or ammonium soaps. Metallic soaps are commercially important as they find use in diverse applications such as driers in paints or inks, components of lubricating greases, heat stabilizers for plastics (especially PVC), catalysts and water proofing agents, fuel additives and cosmetic products amongst others. Many of these applications are related to the thermal properties of these compounds and the thermal behaviour of metal soaps in terms of decomposition processes is of great importance. Rubber seed oil (RSO) which is an unsaturated triglyceride abundantly available in Nigeria, India and Australia is an excellent starting material for metal soaps. In this study rubber seed oil having $2.2 \%$ myristic acid, $7.6 \%$ palmitic acid, $10.7 \%$ stearic acid, $20.61 \%$ oleic acid, $36.62 \%$ linoleic acid, 22.5\% linolenic acid was used in making barium, calcium, cadmium and zinc soaps. The thermal behaviour of soaps $(\mathrm{Ba}, \mathrm{Ca}, \mathrm{Cd}$ and $\mathrm{Zn})$ of rubber seed oil for use as additives in the processing of poly(vinyl chloride) (PVC) was investigated by thermal gravimetry and differential
\end{abstract}

D. Balköse

Department of Chemical Engineering, Izmir Institute of Technology, Izmir, Turkey

T. O. Egbuchunam ( $\square)$

Department of Chemistry, Federal University of Petroleum

Resources, Effurun, Nigeria

e-mail: tessychunam@yahoo.com

F. E. Okieimen

Department of Chemistry and Centre for Biomaterials Research, University of Benin, Benin City, Nigeria scanning calorimetry. The stability of the soaps was examined by thermogravimetry up to $873 \mathrm{~K}$ at a constant heating rate of $10{ }^{\circ} \mathrm{C} \mathrm{min}^{-1}$. The soaps were found to be thermally stable up to $473 \mathrm{~K}$ as they recorded less than $5 \%$ mass loss at this temperature with values of apparent activation energy for decomposition varying from 52 to $96 \mathrm{~kJ} \mathrm{~mol}^{-1}$. Differential scanning calorimetric studies of the soaps revealed melting and decomposition behaviour of metal soaps.

Keywords Metal soaps - Rubber seed oil ·

Thermal behaviour

\section{Introduction}

Recently, the use of renewable resources in the preparation of various industrial materials has revitalized considerable interest because of environmental concerns. Natural oils are considered to be the important class of renewable sources [1] and can be obtained from naturally occurring plants such as sunflower, rubber, cotton, linseed, etc., they consist predominantly of triglycerides.

The seed of rubber (Hevea brasiliensis) is a source of unsaturated long-chain fatty acids $\left(\mathrm{C}_{18}\right)$ of about $80 \%$ [2]. This oil seed crop has been cultivated on a commercial scale for several years and is abundantly available in Nigeria, India and Australia. The fatty acid composition enables its use in cosmetic formulations, metal soaps, alkyd resins and the production of biodiesel [2-5].

Metal soaps based on vegetable oils are increasingly been used in applications such as heat stabilizers for plastics (especially PVC), waterproofing agents, fuel additives, cosmetic products, etc. [3]. Metal soaps prepared from rubber seed oil have been shown to have a stabilizing effect on flexible and rigid PVC [2, 6-9] and as plasticizer 
for acrylonitrile rubber [4] amongst other uses. However, little attention has been paid to the thermal behaviour of these additives.

Thermogravimetry (TG) is the measurement of the mass change of a material as a function of temperature and time and the apparent kinetic parameters often obtained from the TG measurements are often used to represent the behaviour of the material's decomposition in general $[10,11]$. The commonly used approach to determine the apparent kinetic parameters is first to measure the mass loss behaviour during the material's decomposition and then to use the Arrhenius equation to fit the mass loss data which provides the kinetic parameters.

To gain further understanding of their thermotropic behaviour, the soaps were investigated by DSC over the range $298-873 \mathrm{~K}$, at a heating rate of $10{ }^{\circ} \mathrm{C} \mathrm{min}^{-1}$.

We report in the present communication the thermal behaviour of barium, calcium, cadmium and zinc soaps obtained from rubber seed oil (RSO) prepared by precipitation.

\section{Materials}

Rubber seed oil

Rubber seed oil was obtained from Rubber Research Institute of Nigeria, Iyanomon, Benin City. The typical triglyceride compositions of the oil have been reported previously [8].

Preparation of rubber seed oil derivatives

Metal (Ba, Ca, Cd and Zn) soaps of RSO were prepared by the precipitation technique [3]. In a typical precipitation reaction, sodium soap of RSO (prepared by mixing $0.01 \mathrm{~mol}$ RSO and $0.1 \mathrm{~mol} \mathrm{NaOH}$ ) was used as the starting material. $5 \mathrm{~g}(0.016 \mathrm{~mol})$ of the sodium soap was dissolved in $200 \mathrm{~mL}$ of deionized water at $343 \mathrm{~K}$ in a water bath. The $\mathrm{pH}$ value was measured to be 9.01 at $298 \mathrm{~K}$. After the complete dissolution of the sodium soap, an excess (30\%) of the appropriate metal salt (dissolved in $100 \mathrm{~mL}$ of deionized water) was slowly added with continuous stirring. The precipitated metal soap was washed severally with $50 \mathrm{~mL}$ of deionized water, filtered, air-dried and dried in oven under $400 \mathrm{mmHg}$ vacuum at $303 \mathrm{~K}$. The amounts of metal salts used in the production of $\mathrm{Ba}, \mathrm{Ca}, \mathrm{Cd}$ and $\mathrm{Zn}$ soaps were $2.541 \mathrm{~g}$ (0.01 mol; $30 \%$ excess) of $\mathrm{BaCl}_{2} \cdot 2 \mathrm{H}_{2} \mathrm{O}, 1.530 \mathrm{~g}(0.01 \mathrm{~mol}$; $30 \%$ excess) of $\mathrm{CaCl}_{2} \cdot 2 \mathrm{H}_{2} \mathrm{O}, 2.906 \mathrm{~g}(0.016 \mathrm{~mol} ; 100 \%$ excess) of $\mathrm{CdCl}_{2}$ and $4.345 \mathrm{~g}$ ( $0.015 \mathrm{~mol} ; 80 \%$ excess) of $\mathrm{ZnSO}_{4} \cdot 7 \mathrm{H}_{2} \mathrm{O}$, respectively.

\section{Methods}

Thermal properties

Thermal analysis was carried out to observe the changes in thermal behaviour (decomposition temperature) of the soap samples. The soaps were heated from 298 to $873 \mathrm{~K}$ at a rate of $10{ }^{\circ} \mathrm{C} \mathrm{min}^{-1}$ under nitrogen atmosphere to remove all corrosive gases evolved in the degradation process and to avoid thermo-oxidative degradation.

To study the thermal processes responsible for the changes in the crystalline state of the soap samples, differential scanning calorimetry measurements were carried out. Samples were heated up to $873 \mathrm{~K}$ at a heating rate of $10{ }^{\circ} \mathrm{C} \mathrm{m^{-1 }}$ under $40 \mathrm{~cm}^{3} \min ^{-1}$ nitrogen gas flow.

\section{Results and discussion}

Thermogravimetric analysis

Figure 1 shows the TG curves of the metal soaps of rubber seed oil.

The curves present a one-step decomposition process except for Ca soap. From the characteristic temperatures in TGA curves, it can be seen that the metal soaps of rubber seed oil appear to be thermally stable at temperatures lower than $473 \mathrm{~K}$. These materials lose about $3 \%$ of mass below this temperature, about $10 \%$ of their mass at temperatures between 473 and $573 \mathrm{~K}$, followed by an abrupt mass loss after $593 \mathrm{~K}$. A $40 \%$ mass loss was observed at $753 \mathrm{~K}$ for the metal soaps of RSO except for $\mathrm{Ca}$ which appeared more susceptible to thermal degradation. The residual mass of the metal soap samples at $873 \mathrm{~K}$ are $51.1 \%$ for Ba soap; $13.8 \%$ for Ca soap; $48.7 \%$ for Cd soap; $49.8 \%$ for $\mathrm{Zn}$ soap.

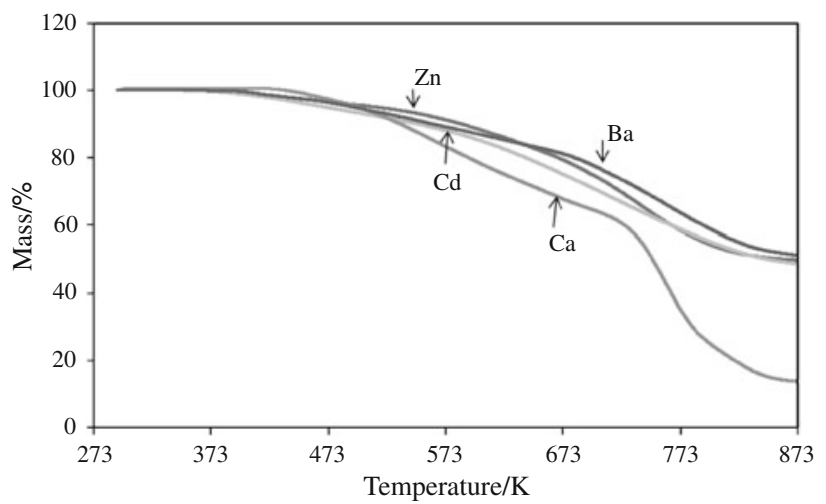

Fig. 1 TG curves of metal soap samples obtained from rubber seed oil 


\section{Degradation kinetics}

Theory

Solid-state thermal decomposition reactions are generally homogenous in nature and for many kinetic processes; a rate of reaction may be expressed as a product of a temperature-dependent function. The decomposition kinetics of the metal soaps of RSO was derived from the TG curves by applying an analytical method proposed by Broido [12]. Kinetic studies of this apparently simple reaction relates the rate of mass loss at a constant temperature to the fractional decomposition

$\frac{\mathrm{d} \alpha}{\mathrm{d} t}=k f(\alpha)$

where $\mathrm{d} \alpha / \mathrm{d} \alpha$ is the rate of mass loss, $\alpha$ is the fractional decomposition at any time and is given by

$\alpha=\frac{W_{\mathrm{t}}-W_{\infty}}{W_{\mathrm{o}}-W_{\infty}}$

where $W_{\mathrm{o}}, W_{\mathrm{t}}$ and $W_{\infty}$ represent the initial mass, residual mass at time $t$, and residual mass at the end of degradation, respectively. The term $f(\alpha)$ is a function of $\alpha$, namely

$f(\alpha)=(1-\alpha)^{n}$

The rate constant, $k$, is dependent on the reaction temperature according to the Arrhenius equation

$k=A \exp ^{(-E / R T)}$

where $A$ is the pre-exponential factor, $E$ is the activation energy, $R$ is the gas constant, and $T$ is the reaction temperature. Combining Eqs. 2, 3 and 4 yields

$\frac{\mathrm{d} \alpha}{\mathrm{d} t}=A(1-\alpha)^{n} \exp ^{-(E / R T)}$

Because $\quad \mathrm{d} \alpha / \mathrm{d} t=(\mathrm{d} \alpha / \mathrm{d} T)(\mathrm{d} T / \mathrm{d} t)=\beta(\mathrm{d} \alpha / \mathrm{d} T), \quad$ the integrated form of Eq. 5 can be expressed as

$F(\alpha)=\int_{0}^{\alpha} \frac{\mathrm{d} \alpha}{(1-\alpha)^{n}}=\frac{A}{\beta} \int_{T_{\mathrm{o}}}^{T} \exp ^{-(E / R T)} \mathrm{d} T$

Here $\beta$ is the heating rate.

Published methods of deriving kinetic parameters from TG data centre on Eq. 6 using either a single curve obtained at a constant heating rate or multiple curves with different heating rates. The Broido's method is one of the simplest integral method using a single curve and assumes $\exp ^{-E / R T} \cong\left(T_{\mathrm{m}} / T\right)^{2} \exp ^{-E / R T}$ where $T_{\mathrm{m}}$ is the temperature of maximum reaction, and $n=1$. The Broido's equation:

$\ln \{\ln (1 / \alpha)\}=-\frac{E}{R T}+\ln \frac{\left(R Z T_{\mathrm{m}}^{2}\right)}{\beta E}$

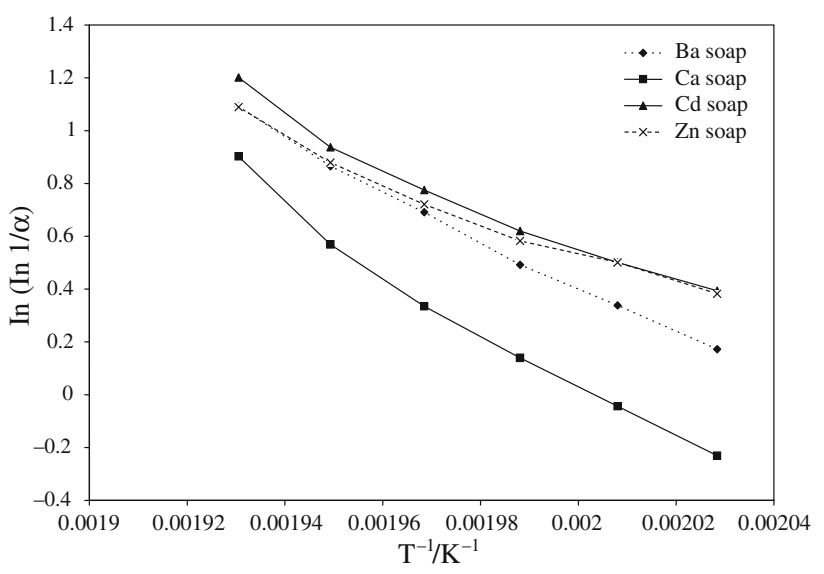

Fig. 2 Broido's plot for metal soap samples obtained from rubber seed oil

allows the value of $E$ to be obtained from the slope of the linear plot of $\ln (\ln 1 / \alpha)$ vs. $1 / T$.

The ultimate objective is to determine the apparent activation energy associated with the overall weight loss behaviour rather than the exact chemical mechanisms during the decomposition process. The slope of the plot of $\ln (\ln 1 / \alpha)$ vs. $1 / T$ is a straight line, as shown in Fig. 2 from which the energy of activation, $E$, was calculated and values given in Table 1.

The values of $E_{\mathrm{a}}$ appear not consistent with the relative stabilities of the soaps observed from Fig. 1. The factors that may influence the value of activation energy include molecular weight of the fatty acid, chain length and the nature and amount of impurities present in the additive. The concept of activation energy assumes that thermal degradation is a single event rather than separate reaction processes.

\section{DSC measurements}

To gain further understanding of their thermal behaviour, the soaps were investigated by DSC over the range 298-873 K, at a heating rate of $10{ }^{\circ} \mathrm{C} \mathrm{min}^{-1}$. The thermodynamic parameters calculated for endothermic processes taking place during the thermal process (associated in principle with phase transitions) are listed in Table 2. Typical DSC

Table 1 Activation energies for the thermal decomposition of metal soaps of RSO

\begin{tabular}{ll}
\hline Metal soap & $E_{\mathrm{a}} / \mathrm{kJ} \mathrm{mol}^{-1}$ \\
\hline Ba soap & 96.03 \\
Ca soap & 83.14 \\
Cd soap & 56.43 \\
Zn soap & 51.76 \\
\hline
\end{tabular}


Table 2 Transition temperatures accompanying the decomposition of metal soaps obtained from RSO

\begin{tabular}{llllll}
\hline Metal soap & Endothermic peak/K & $T_{\text {(onset) }} / \mathrm{K}\left(\mathrm{T}_{1}\right)$ & $T_{\text {(endset) }} / \mathrm{K}\left(\mathrm{T}_{2}\right)$ & Mass loss/\% & Transition occurring \\
\hline Ba soap & 334.13 & 305.12 & 357.65 & 0.00 & Melting \\
& 514.00 & 463.00 & 633.02 & 12.52 & Decomposition \\
& 747.06 & 723.83 & 770.50 & 4.57 & Decomposition \\
Ca soap & 334.84 & 324.27 & 385.78 & 0.00 & Melting \\
& 738.20 & 686.74 & 781.41 & 35.41 & Decomposition \\
Cd soap & 336.21 & 333.01 & 350.62 & 0.00 & Melting \\
& 464.60 & 460.80 & 466.10 & 0.35 & Melting \\
& 630.10 & 585.54 & 668.54 & 11.08 & Decomposition \\
Zn soap & 731.50 & 702.61 & 762.08 & 3.02 & Decomposition \\
& 354.00 & 337.35 & 368.98 & 0.00 & Melting \\
& 424.80 & 400.10 & 479.80 & 3.00 & Decomposition \\
& 600.10 & 564.00 & 629.20 & 745.10 & Decomposition \\
\hline
\end{tabular}
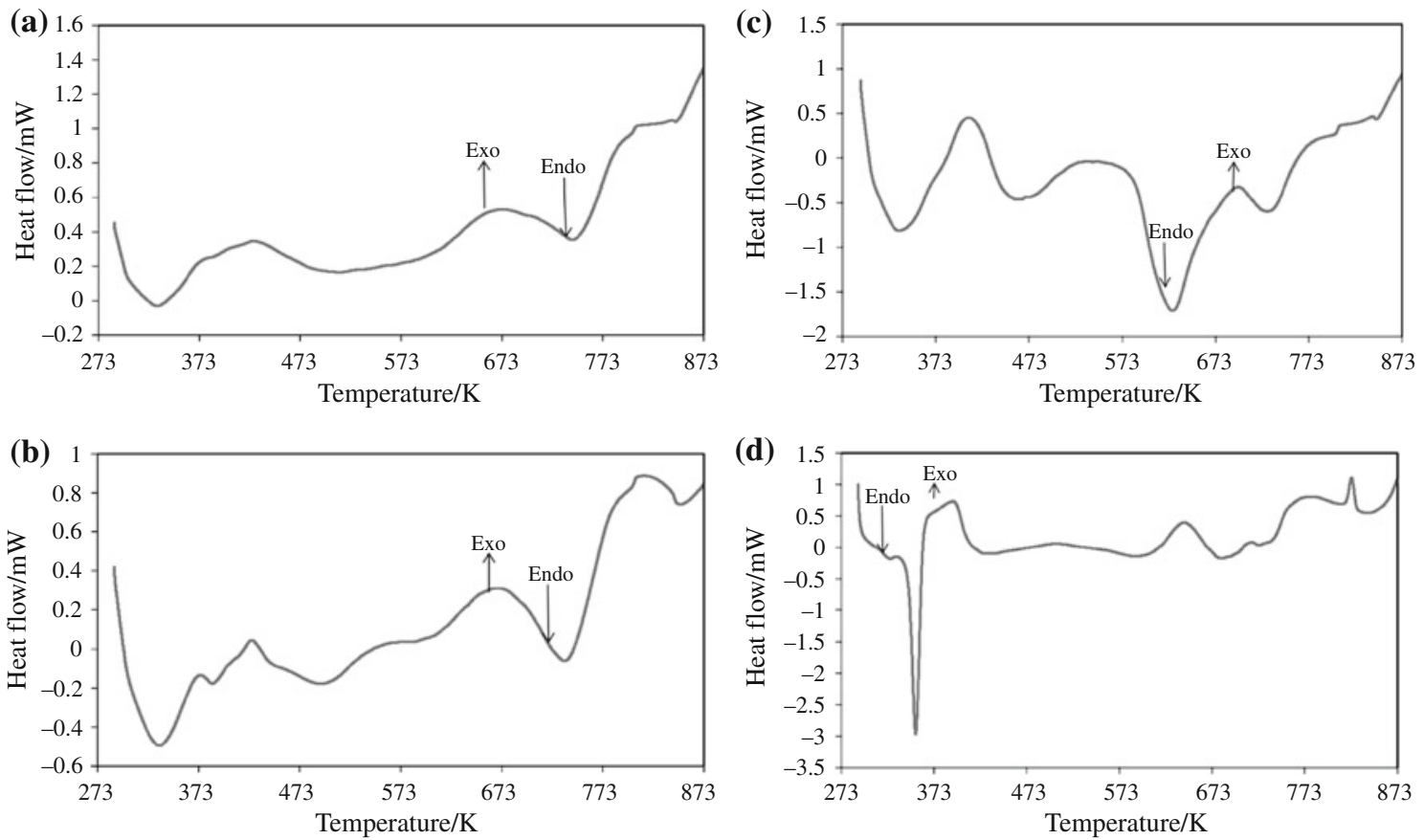

Fig. 3 DSC curves for soaps obtained from rubber seed oil. a Ba soap, b Ca soap, c Ca soap, d Zn soap

curves for the soaps are shown in Fig. 3a-d. The DSC curves show a single endotherm below $373 \mathrm{~K}$ for all the soaps corresponding to melting as no mass loss was observed.

\section{Conclusion}

In this study, the metal soaps of barium, cadmium, calcium and zinc were prepared by precipitation technique. The onset of melting for all the soaps occurred well below $373 \mathrm{~K}$ and the values of activation energy for decomposition obtained by fitting the data obtained from thermogravimetric analysis into the Broido's equation were between 52 and $96 \mathrm{~kJ} \mathrm{~mol}^{-1}$.

The present study has shown that the metal soaps obtained from RSO are expected to be a new class of biodegradable additives for PVC from inexpensive renewable resources, contributing to global sustainability. 


\section{References}

1. Güner FS, Yağci Y, Erciyes AT. Polymers of triglyceride oils. Prog Polym Sci. 2006;31:633-70.

2. Okieimen FE. Studies in the utilization of epoxidised vegetable oils as thermal stabilizer for poly (vinyl chloride). Ind Crops Prod. 2002;15:71-5.

3. Gonen M, Balköse D, Inal F, Ulku S. Zinc stearate production by precipitation and fusion processes. Ind Eng Chem Res. 2005;44:1627-33.

4. Joseph R, Alex R, Vinod VS, Premalatha CK, Kuriakose B. Studies on epoxidised rubber seed oil as plasticizer for acrylonitrile rubber. J Appl Polym Sci. 2003;88:668-73.

5. Aigbodion AI, Okieimen FE, Obazee EO, Bakare IO. Utilization of maleinized rubber seed oil and its alkyd resin as binder in water-borne coatings. Prog Org Coat. 2003;46:28-31.

6. Balköse D, Egbuchunam TO, Okieimen FE. Formulation and properties evaluation of $\mathrm{PVC} /($ dioctly phthalate)/(epoxidised rubber seed oil) plastigels. J Vinyl Addit Technol. 2008;14:6572.

7. Okieimen FE, Egbuchunam TO, Balköse D. Thermal stabilization of PVC with metal soaps of rubber seed oil: Thermogravimetric studies. Niger J Appl Sci. 2006;24:144-51.

8. Okieimen FE. Thermal stabilization of PVC: Effect of rubber seed oil derivatives on the thermal degradation of PVC. J Sci Ind Res. 2000;59:563-8.

9. Okieimen FE, Ebhoaye JE. Studies in the thermal degradation of poly (vinyl chloride). J Appl Polym Sci. 1993;48:1853-8.

10. Yang J, Miranda R, Roy C. Using the DTG curve fitting method to determine the apparent kinetic parameters of thermal decomposition of polymers. Polym Degrad Stab. 2001;73:455-61.

11. Moreira APD, Souza BS, Teixeira AMRF. Monitoring of calcium stearate formation by thermogravimetry. J Therm Anal Calorim. 2009;97:647-52.

12. Broido A. A simple, sensitive, graphical method of treating thermogravimetric analysis data. J Polym Sci. 1969;7:1761-73. 